\title{
Integration of Multiple Control Systems in a Combined Cycle Power Plant
}

\author{
Mr. Anshuman Bhalla \\ P.E. FIEAust CPEng FSEng \\ Professional Engineer P.E. in Control Sytems in the State of California, USA \\ Fellow FIEAust - From the Institution of Engineers Australia \\ Fuctional Safety Engineer FSEng - From TUV Rheinland, Germany \\ Working as a "Manager - Instrumentation and Control Systems" at AES Corporation \\ 690 North Studebaker Rd, Long Beach, California 90803, USA
}

\begin{abstract}
This paper outlines the engineering challenges involved in integrating multiple control systems in a power plant.

Combined cycle power plants utilize gas turbines, steam turbines, HRSG and BOP equipment for generating electrical power. Individual control systems are supplied by OEM of gas turbines, steam turbines and BOP equipment. Package systems like water treatment plants, auxiliary boilers, sewer pump stations and fuel gas compressors also contain PLC based control systems.
\end{abstract}

This creates a situation where integration of multiple control systems becomes the necessity for producing power. Plants where control systems are not properly integrated can often experience nuisance tripping, efficiency and heat rate issues and performance issues, making the power plant unreliable.

The integration of different makes and models of DCS and PLC control systems is a complex engineering process. The Control system engineers have to keep the overall reliability of the plant in mind while designing the network architecture of the plant's control system. The reliability requirements decide the level of redundancy at controllers, networks, servers and input/output (IO) module levels.

The selection of network topology and protocols are of vital importance. The OPC protocol for frontend communication between DCS servers, Profibus DP protocol for communication with electrical switchgear and DNP protocol for communication between PLC and SCADA are some of the available options. The network topology options are Ring network, star network, double ring, double star or Mesh network for system integration. Standardization of protocols and networks are necessary across multiple platforms to minimize complexity, reduce the spare requirements and ease of maintainability. Fiber optic cables, media converters, switches, routers, servers and workstations should be standardized for seamless integration.

Many of the power plants in North American market fall under NERC compliance requirements. Cyber security compliance and physical as well as logical security compliance is considered while integrating multiple control systems.

In the $21^{\text {st }}$ century, information technology (IT) is greatly influencing power plant control system design and optimization.
Virtualization of the servers and workstations is being implemented by many power plant owners instead of using physical machines. Centralized control domain for firmware and patch management is being considered. Data centers and/or Cloud computing can be considered for data historization and centralization.

The complexities involved in combined cycle power plant operations can be greatly minimized if control systems are properly integrated, sequences are automated and control loops are properly tuned. Sequence of events recording (SOE) should be considered to analyze trips and runback events. Alarm rationalization should be considered to avoid any alarm flooding events.

In conclusion, the integration of multiple control systems in a combined cycle power plant requires a multi-dimensional approach. The communication, networks, protocols and IT play an important role in integration. Standardization should be considered for maintainability and ease of operations.

Keywords-Control System, DCS, PLC, SCADA, Power Plant, Protocol, Network, Gas turbine, Steam turbine, BOP, Integration, Standardization, Combined cycle power plant, Gas fired power plant, Power station, Fossil fired power plant

\section{INTRODUCTION}

In the combined cycle power industry, it is a common practice by the Original Equipment Manufacturer (OEM) to supply individual control systems for rotating machines, HRSG and BOP equipment. A typical combined cycle power plant ends up having separate DCS and PLC based control systems for gas turbine, steam turbine and BOP systems. In addition, there are PLC based systems for Fuel Gas Compressors, Auxiliary Boilers, Demineralized Water treatment plant and Sewer pump stations. A combined cycle power plant will have reliability, safety, operability and maintainability issues unless the controls systems are properly integrated and work as a single plant control system. 


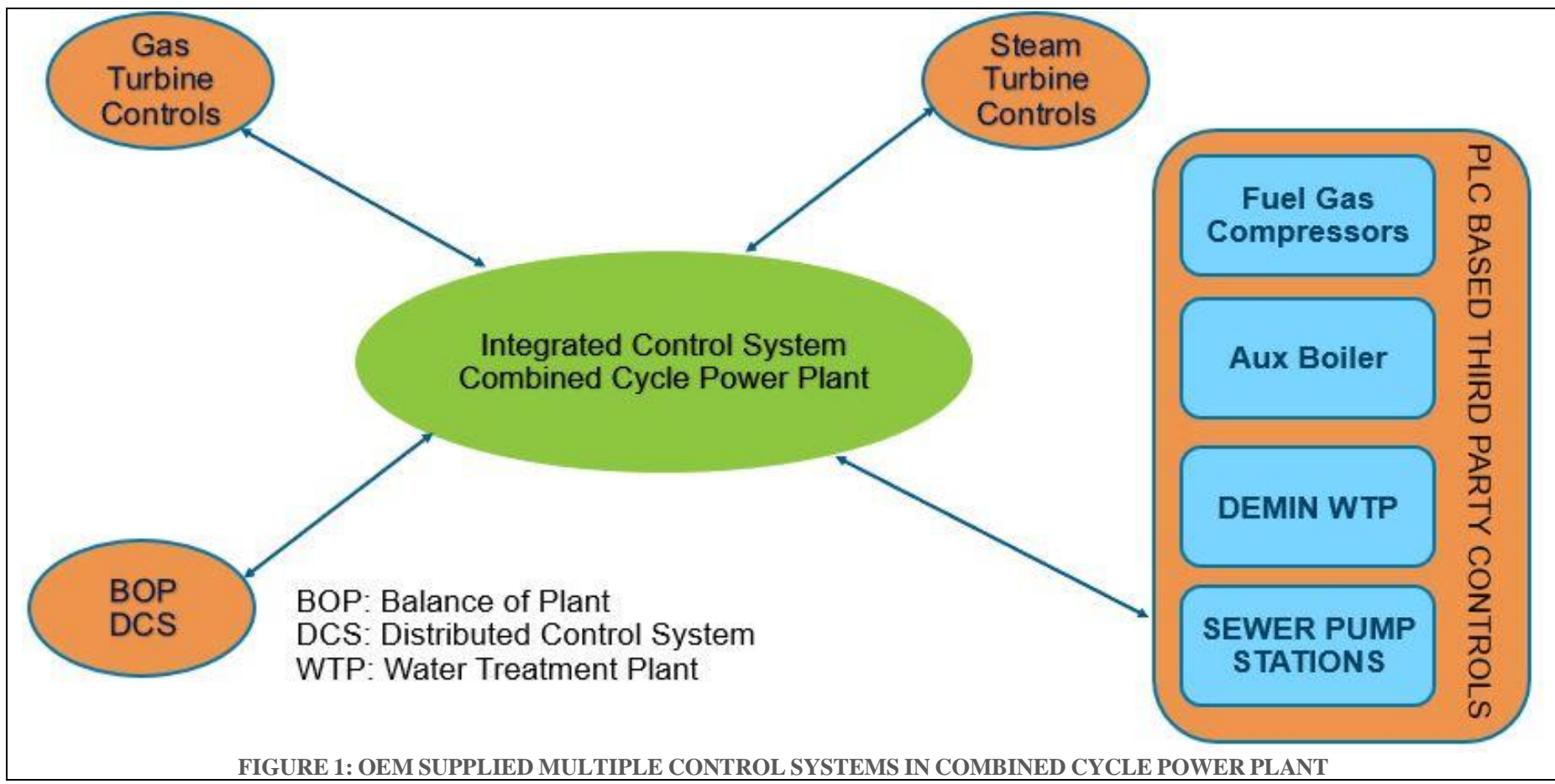

\section{PROBLEMS DUE TO IMPROPER INTEGRATION OF CONTROL SYSTEMS}

Owners and operators of a combined cycle power plant can face multiple issues, if control systems are not properly integrated:
a. Nuisance Tripping
b. Frequent Runbacks of Gas turbine or Steam turbine c. Frequent and unplanned Bypass operation prevailing
in the Plant - Bypass scenario where the steam
turbine has tripped and Gas turbines and HRSG's are running, will result in loss of production
d. Reliability and Availability requirements of the power plant are not met
e. Efficiency and Heat Rate problems
f. Adverse effect on Operability and Maintainability of Plant

\section{INTEGRATION DURING DESIGN - A STANDARDIZED APPROACH}

Due consideration should be given in the design stage to properly integrate multiple control systems in the combined cycle power plant. Hardware and Software shall be standardized across multiple platforms.

a. Standardize Control System Hardware - Servers, Clients, Switches, Routers, Fiber Optic Cables, Media Converters shall be standardized

b. Standardize Control System Software - Select single primary language for programming (SAMA logic or FBD - Functional Block Diagrams)

c. Standardize Graphics - Header, Footer, Navigation, Background Color, Animation of graphics shall be standardized across multiple platforms

d. Standardize Alarms - Alarm Priority, Alarm Color, Alarm Groups i. Implement Alarm Rationalization to prevent Alarm Flooding

ii. Implement Global Acknowledgement and Reset of Alarms from a centralized control system

\section{NETWORKS AND PROTOCOLS - BACKBONE OF A CONTROL SYSTEM}

Selection of networks and protocols, and more specifically standardization of networks and protocols plays a vital role in the integration of control systems. Networks and protocols are the backbone of any control system.

a. Select Single Network Topology across Multiple Control Systems - Ring or STAR Network (Redundant Ring or Redundant STAR can be selected for higher reliability plants)

b. Select Single Protocol across Multiple Control Systems

i. OPC (OLE for Process Control) protocol for Frontend communication (i.e. between two DCS systems or between two servers)

ii. Profibus DP (Decentralized Peripherals) or Foundation Fieldbus protocol for MCC/Switchgear communication interface with DCS

iii. DNP (Distributed Network Protocol) for PLC and SCADA COMS

c. Data Exchange Philosophy (for High Reliability Plants): Select signals that needs to be hardwired and signals that can be exchanged on communication interface between multiple control systems 
i. Hardwired Signals to be used - For Controls, Interlocks, Trips and Runback

ii. Signals through COMS can be used - For Indications, Alarms and Trends

iii. Signals through Redundant COMS - Can be used for Controls and Interlocks (provided reliability study is conducted)

\section{RELIABILITY STUDY FOR PROPER INTEGRATION}

Quantitative Reliability study should be conducted during the design stage to understand the single point of failures in the control system. a. Perform FTA (Fault Tree Analysis) or RBD (Reliability Block Diagram) for quantitative reliability analysis

b. Identify Single Point of Failures in the Control System

c. Consider Redundancy of Controllers, Database Servers and Communication Interfaces, depending upon the Availability Requirements of the plant. As a general practice, for power plants having more than $90 \%$ availability requirements, redundancy of controllers, servers and Communication links are recommended.

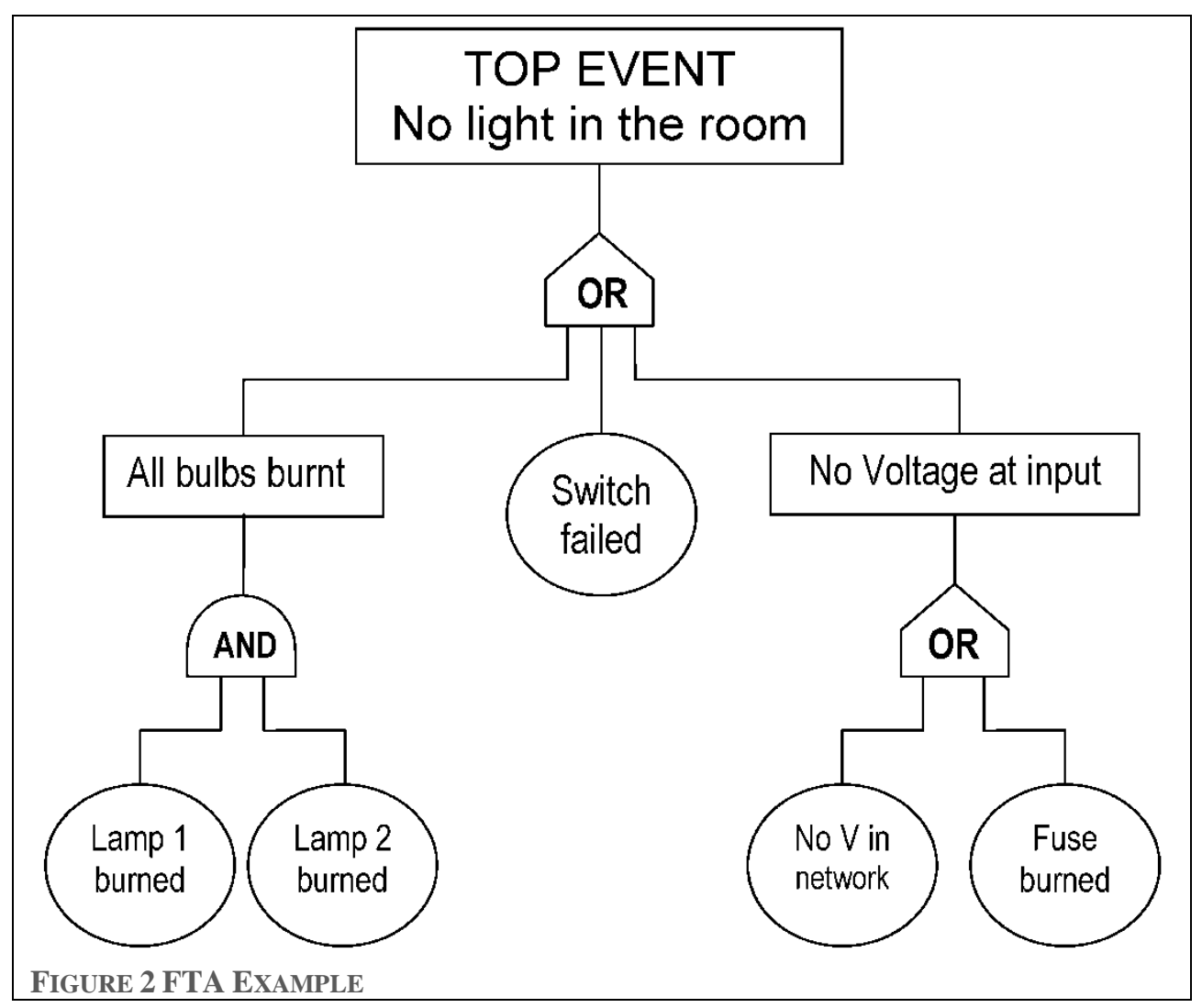

\section{CYBER SECURITY FOR INTEGRATED CONTROL SYSTEM}

The North American Reliability Corporation (NERC) Standards CIP-002 through CIP-009 provide a cyber security framework for the identification and protection of critical cyber assets:

a. Implement the NERC regulations for low, medium or high impact site as per the plant classification.

b. Implement Firewall for any external COMS to the plant control system

c. Use Routers for LAN and WAN segregation

d. Control Network, Monitoring Network and Corporate Network shall be separated from each other.

e. Both physical and logical security of networks and COMS shall be considered.

\section{USE OF INFORMATION TECHNOLOGY FOR CONTROL SYSTEM INTEGRATION}

IT (Information Technology) is playing a vital role in the integration of multiple control systems. The current trends in the IT practices, that are being deployed by many Power plant owners are as follows:

a. Virtualization of servers and clients instead of using physical machines

b. Use of data centers or cloud computing for storage of historized data - instead of using local historian

c. Implementation of RCC (Remote Control Center) to remotely control and operate power plant from a distant location

d. Implement centralized control domain across multiple control system platforms for patch management and user access 


\section{AUTOMATION AND PROCESS CONTROL - KEY ELEMENT OF CONTROL SYSTEM INTEGRATION}

Control systems are integrated by achieving an appropriate level of automation and process control in the power plant. The following considerations are recommended for combined cycle power plant automation:

a. Sequential start-up and shutdown of combined cycle power plant should be considered - For operational efficiency

b. The level of automation to be done in the plant depends upon several factors including cost and the number of operators running the plant. Highly automated plants can achieve a single button start, provided the commercial and operational benefits are justified for a single button start

c. Process Control and automation of BFP (Boiler Feed Pumps), CCW (Closed Cooling Water) Pumps, Condensate Pumps, ACC (Air Cooled Condenser) Fans, ACHE (Air Cooled Heat Exchanger) Fans, air compressors and other major BOP equipment should be considered

d. Drum level controls (both three element and single element) are very important from controls perspective and they should be properly tuned e. SOE (Sequence of Events Recording) should be implemented to analyze trips and runbacks conditions

\section{CONCLUSION}

A multi-dimensional and multi layered approach is required during the design and construction stages to integrate multiple control systems in a combined cycle power plant. Standardization of hardware and software should be considered. Selection and standardization of networks and protocols is very important. Reliability and process control requirements decides the level of integration to be done in the plant.

Lesser the number of control systems, the better and easier it is to integrate.

Integration is more of an art than a science. Experienced and skilled Control System Engineers are required to properly integrate multiple control systems in a combined cycle power plant.

The principals and practices outlined in this paper are also applicable to LNG plants, oil and gas refineries, petrochemical plants and other process industries that utilizes PLC and DCS based controls for process automation.

\section{REFERENCES}

[1] ANSI/ISA-18.2-2009, "Management of Alarm Systems for the Process Industries", 23 June 2009

[2] Bela G. Liptak, "Process Measurement and Analysis", Fourth Edition, Volume I

[3] Bela G. Liptak, "Process Control and Optimization", Fourth Edition, Volume II 